\title{
Review
}

Neuropsychobiology

\section{Are Respiratory Abnormalities Specific for Panic Disorder? A Meta-Analysis}

\author{
Massimiliano Grassi ${ }^{\mathrm{a}}$ Daniela Caldirola ${ }^{\mathrm{a}}$ Nunzia Valentina Di Chiaro ${ }^{\mathrm{a}}$ \\ Alice Riva ${ }^{a}$ Silvia Daccò ${ }^{a}$ Maurizio Pompili ${ }^{b}$ Giampaolo Perna ${ }^{a, c, d}$ \\ ${ }^{a}$ Department of Clinical Neurosciences, Villa San Benedetto Hospital, Hermanas Hospitalarias, FoRiPsi, \\ Albese con Cassano, and b Sant'Andrea Hospital, Sapienza University of Rome, Rome, Italy; ' ${ }^{\text {Department of }}$ \\ Psychiatry and Neuropsychology, Faculty of Health, Medicine and Life Sciences, University of Maastricht, \\ Maastricht, The Netherlands; ${ }^{\mathrm{d}}$ Leonard M. Miller School of Medicine, University of Miami, Miami, Fla., USA
}

\section{Key Words}

Panic attacks · Social phobia · Anxiety disorders · Affective disorders · Biological psychiatry

\begin{abstract}
Objectives: There is evidence of baseline respiratory abnormalities in panic disorder (PD), but whether they are specific to $P D$ remains unclear. To investigate this issue, we metaanalyzed results from studies comparing baseline respiratory and hematic variables between subjects with PD and subjects with other anxiety disorders. Methods: A literature search in bibliographic databases was performed. Fixed-effects models were applied. Several moderator analyses and publication bias diagnostics were performed. Results: We found: (1) significantly lower mean end-tidal partial pressure of $\mathrm{CO}_{2}$ (et-pCO $\mathrm{CO}_{2}$ ) in subjects with PD than in those with social phobia (SP) or generalized anxiety disorder (GAD), and (2) higher mean respiratory rate, lower venous et- $\mathrm{pCO}_{2}$ and $\mathrm{HCO}_{3}{ }^{-}$concentration in subjects with PD than in those with SP. No publication bias was found. Conclusions: Subjects with PD show a condition of baseline hyperventilation when compared to subjects with SP or GAD. Hematic variables suggest that the hyperventilation may be chronic. These results support the idea that baseline respiratory abnormali-
\end{abstract}

ties are specific to PD pathophysiology. Further studies are needed to clarify whether these abnormalities are related to a malfunction of the respiratory system or to specific cognitive/emotional/behavioral factors in this population.

(c) 2014 S. Karger AG, Basel

\section{Introduction}

A link between panic disorder (PD) and respiration is well established. The presence of prominent respiratory symptoms during panic attacks, the behavioral and respiratory hypersensitivity to hypercapnic gas mixture-inhalation in patients with $\mathrm{PD}$, and a specific bidirectional association between PD and respiratory diseases support this link $[1,2]$. Several theories sharing the idea of a causal relationship between aberrant respiratory regulation and panic have been developed [2-5], even though the nature of this respiratory abnormality is not yet fully understood.

We recently performed a meta-analysis of studies that compared PD and control groups on baseline respiratory variables and hematic variables related to the respiratory function [6]. We found higher baseline mean minute ventilation $(\mathrm{MV})$, lower end-tidal partial pressure of $\mathrm{CO}_{2}$

\section{KARGER}

E-Mail karger@karger.com

www.karger.com/nps
C 2014 S. Karger AG, Basel

0302-282X/14/0701-0052\$39.50/0
Daniela Caldirola, $\mathrm{PhD}, \mathrm{MD}$

Department of Clinical Neurosciences

Villa San Benedetto Hospital, Hermanas Hospitalarias, Via Roma 16

IT-22032, Albese con Cassano (Italy)

E-Mail caldiroladaniela@gmail.com 
(et-pCO $\mathrm{pC}_{2}$ ) and lower venous $\mathrm{pCO}_{2}$ in subjects with $\mathrm{PD}$, indicating a condition of baseline hyperventilation. Our results of reduced $\mathrm{HCO}_{3}{ }^{-}$(bicarbonate ion) and $\mathrm{PO}_{4}{ }^{-}$ (phosphate ion) venous concentrations in these subjects suggest that hyperventilation may be chronic and not simply related to high anxiety levels the subjects may have experienced during the respiratory assessment. Finally, we also found indications of higher variability of $M V$, respiration rate (RR) and tidal volume (TV), higher $\mathrm{RR}$ and TV irregularity, and a higher rate of sighs and apneas in the respiratory patterns of subjects with PD.

Whether these respiratory abnormalities are specific to $\mathrm{PD}$ or shared with other anxiety disorders (ADs) remains an open issue. Available studies comparing baseline respiratory variables between subjects with $\mathrm{PD}$ and those with other ADs yielded mixed results [7-9] and, to the best of our knowledge, published systematic reviews or meta-analyses are lacking.

The aim of our study was to investigate the specificity of the baseline respiratory abnormalities by meta-analysis of the results from all studies comparing baseline respiratory variables between subjects with PD and subjects with other ADs. To clarify this issue may help to better understand the pathophysiology of PD.

\section{Methods}

\section{Inclusion Criteria}

We included studies that fulfilled the following criteria: (1) performed a comparison of respiratory and/or hematic variables related to the respiratory function between subjects with $\mathrm{PD}$, with or without agoraphobia, and subjects with other ADs; (2) variables were measured only in a resting or baseline condition preceding a subsequent stimulation (henceforth we will use the term 'baseline' to refer to both conditions); (3) inclusion of the subjects was not based on the results of previously performed challenges or stimulations; (4) subjects were $\geq 18$ years of age; (5) criteria of AD diagnoses according to DSM-III [10], DSM-III-R [11] or DSM-IV/DSMIV-TR $[12,13]$; (6) was published in a peer-reviewed scientific journal; (7) enough statistical data had to be available to allow the meta-analytic computation, and (8) written in English, French, Spanish or Italian.

\section{Search Procedure}

Literature searches were performed in PubMed, Embase and Psychinfo with this combination of search terms: 'panic* AND (respirat* OR breath* OR hyperventilat* OR (tidal volume) OR (minute ventilation) OR pCO2 OR pO2 OR sigh OR sighs)'. Papers from 1980, when the diagnosis of PD was first introduced in DSMIII [10], to December 31, 2013 were searched. References were screened using a two-step procedure: (1) the titles and the abstracts of all the references were read to select all potentially relevant papers, and (2) the full text was read to identify which studies fulfilled the inclusion criteria. Furthermore, references of all selected papers, relevant reviews and book chapters were screened to find studies potentially missed with the previous search. Each step of the search procedure was independently performed by two of the authors and inconsistencies in the results were discussed and resolved before proceeding.

\section{Effect-size Calculation and Coding of Studies}

For all of the included studies, we calculated the baseline respiratory variable effect sizes of comparisons between subjects with $\mathrm{PD}$, with or without agoraphobia, and subjects with other ADs. Effect sizes were calculated using Hedges' g, a variation of Cohen's $\mathrm{d}$, correcting for biases associated with small sample sizes [14]. When the group mean, standard deviation (SD), variance or standard error of mean and number of subjects were available for both groups, these data were preferably used to calculate the effect size. When some of these data were missing, we looked for other data allowing the effect-size computation, such as unstandardized mean difference as well as $t$ and $p$ values. When the statistics of the variables were available for only subgroups of the diagnostic groups (i.e. male and female), data of the whole diagnostic groups were obtained by pooling subgroup statistics.

Moreover, the following study characteristics were coded and included in the analyses as moderators: (1) subjects who were medication-free for at least 2 weeks before assessment, except for occasional use of benzodiazepines, and subjects completely refraining from occasional use of benzodiazepines for at least $24 \mathrm{~h}$ before the day of the respiratory assessment: yes/no; (2) subjects being screened for medical illnesses and presence of respiratory diseases: yes/no; (3) type of study, i.e. resting/with stimulation; (4) subjects having an inserted catheter during the respiratory assessment: yes/ no; (5) the position of the subjects during respiratory assessment: supine or seated, and (6) psychiatric diagnosis performed by structured or semistructured diagnostic interview: yes/no.

Computation of the effect size and coding of the studies were performed independently by two authors and any discrepancy was resolved before analysis.

\section{Meta-Analytic Statistics}

In the calculation of the summary effect size of each variable (i.e. the estimate of the population effect size resulting from the meta-analysis), every single-study effect size was weighted by its inverse variance to give a larger weighting to studies with large sample sizes than those with small sample sizes. Before excluding a study for not meeting inclusion criterion 7 , we tried to contact the corresponding author (only for studies published not more than 10 years ago) asking for the missing details. When papers did not report enough data for the computation of a nonsignificant effect size and we failed to obtain full details from the authors, we included it inserting a null-effect size in the analysis. In order to increase the reliability of such a procedure, the inclusion was done only if the result of a nonsignificant difference was clearly reported in the paper. Otherwise the comparison was excluded from the analyses; we also excluded studies in which the computation of both significant and nonsignificant effect sizes was not possible (see inclusion criterion 7). Thus, when appropriate, two distinct analyses including and excluding null effect sizes were performed. In order to avoid excessive imprecision of the results, only variables that were explicitly calculated in at least two studies were meta-analyzed. 
A fixed-effects model was calculated for all the variables. We also used a random-effects model only when the number of available studies was at least 10 [6]. Concordance of the results obtained by the two meta-analytical models was considered strongly suggestive of reliable results, while we attempted to clarify the significance of the fixed-effects model and nonsignificance of the random-effects model according to results of moderator analysis. Results obtained only by the fixed-effects model were considered preliminary. A significance level of 0.05 was applied to the summary effect sizes.

A Q statistic and $\mathrm{I}^{2}$ index were used to investigate the heterogeneity of the effect sizes among studies. The significance level of the Q statistic was set at 0.1 as suggested by the authors [15] to adjust for the limited statistical power of this test. $\mathrm{I}^{2}$ can be interpreted as the percentage of the total variability in a set of effect sizes that cannot be attributed only to the sampling error within studies. If the Q statistic resulted significant or $\mathrm{I}^{2}$ suggested heterogeneity, we checked whether the source of this heterogeneity might have been attributed to one single effect size outlying from all others. In this case we repeated the meta-analytic analyses one-by-one removing each effect size. An effect size was considered outlying when its exclusion from the analyses yielded to a resolution of the heterogeneity, and its inclusion during the removal of other effect sizes did not. The one-by-one exclusion procedure was not performable when only two single-study effect sizes were available for comparison.

All analyses were performed with Comprehensive Meta-Analysis (version 2.2.048), a statistical analysis package by Biostat Inc.

\section{Moderator Analyses}

To find possible sources of heterogeneity among the baseline respiratory variable effect sizes, we also performed moderator analyses with the aforementioned study characteristics. We performed separate fixed-effects models within each level of the moderators and then compared them with the between-groups Q statistic. Statistical significance for moderator analysis was set at $\mathrm{p}<$ 0.05 .

\section{Publication Bias}

We performed the Egger's regression test to check for possible publication bias [16] (one-tailed $\mathrm{p}<0.05$ suggesting presence of the bias). We also used the trim-and-fill method from Duval and Tweedie [17] if the summary effect sizes were based on at least 10 studies [18].

\section{Results}

\section{Included Studies}

The literature search yielded 3,582 unique references.

The first screening step (examination of titles and abstracts) identified 25 references potentially including comparisons of respiratory variables between subjects with $\mathrm{PD}$ and those with other ADs. The independent selections were carried out by two of the authors and yielded 23 and 25 references, respectively. The two nonmatching references were included in the total selected refer- ences to be further reviewed in full-text (second step). Thirteen independent studies reported in 14 different papers fulfilled the inclusion criteria and were finally included in the analysis. Eight papers were excluded because the studies they reported did not satisfy the inclusion criteria. One study was excluded because the baseline respiratory variables were measured during daily-life registration [19], another study was excluded because the baseline assessment period contained a 15 -second countdown to the $\mathrm{CO}_{2}$ challenge that was not excluded from the baseline respiratory variables assessment [20] and one more study was excluded due to an inconsistency in the sample size declared in the paper [21].

All details about the inclusion/exclusion of studies are provided as supplementary data (for all online suppl. material, see www.karger.com/doi/10.1159/000364830) and a flowchart of the general inclusion procedure is reported in figure 1.

\section{Computation of Effect size and Coding of Studies}

No reply was received from any author we contacted to obtain missing data. Thus, we excluded these studies or, when possible, inserted null effect sizes in the analyses, as previously described. Descriptions of all the included studies with relevant variables and study-level characteristics coded for each study are reported in table 1 .

Since only unique studies were identified that compared subjects suffering from PD with subjects, respectively, suffering from posttraumatic stress disorder, obsessive-compulsive disorder and simple phobia, no metaanalysis was performable for these comparisons.

Comparisons between PD and Social Phobia. Thirtyeight effect sizes of baseline respiratory variables were calculated: 19 by means, SD and group sizes, while 19 null effect sizes were inserted in the analysis. No disagreements on the calculations among the two authors emerged. Only the variables with at least two effect sizes from two independent studies were meta-analyzed, and these were mean RR (breath/min), TV ( $\mathrm{ml} /$ breath), MV $(\mathrm{l} / \mathrm{min})$, et- $\mathrm{pCO}_{2}(\mathrm{~mm} \mathrm{Hg})$, venous $\mathrm{pCO}_{2}(\mathrm{~mm} \mathrm{Hg})$, $\mathrm{HCO}_{3}{ }^{-}(\mathrm{mmol} / \mathrm{l})$ and $\mathrm{pH}$.

Comparisons between $P D$ and Generalized Anxiety Disorder. Thirty-eight effect sizes were calculated: 28 by means, SD and group sizes, while 19 null effect sizes were inserted in the analysis. Disagreements regarding two effect sizes calculated independently by the two authors were unanimously resolved. Only variables that had at least two effect sizes from two independent studies were suitable to be meta-analyzed, i.e. mean RR (breath/min), $\mathrm{MV}(\mathrm{l} / \mathrm{min})$ and et- $\mathrm{pCO}_{2}(\mathrm{~mm} \mathrm{Hg})$. 


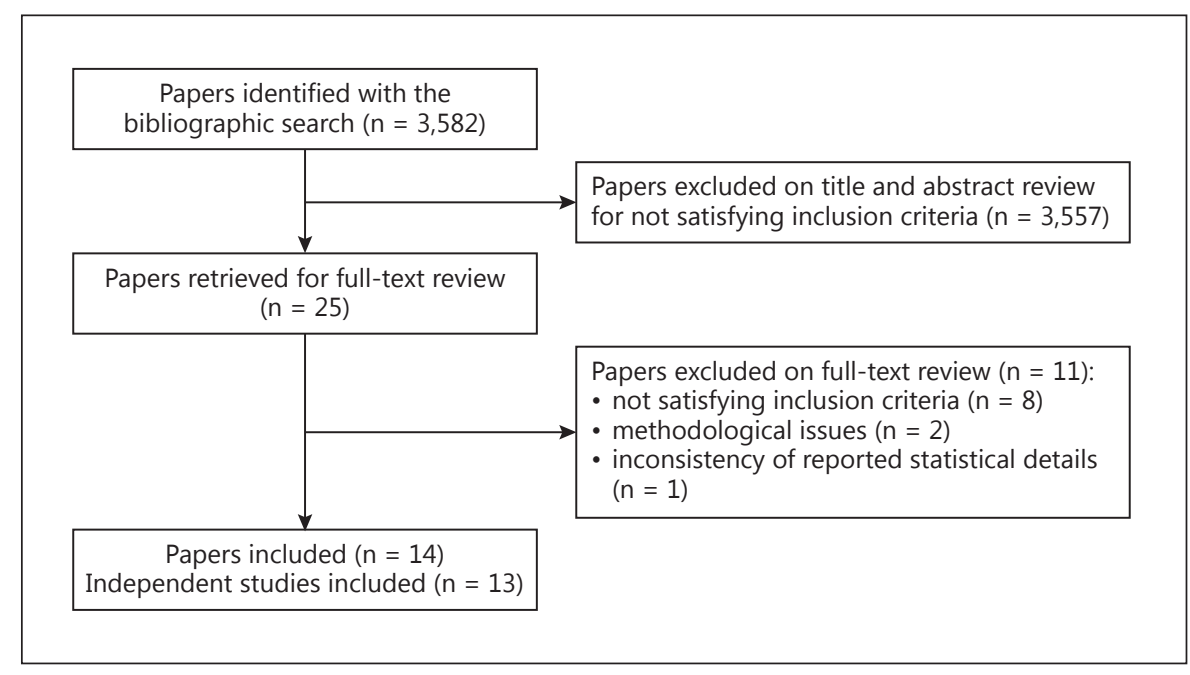

Fig. 1. Study inclusion flowchart.

\section{Meta-Analytic Results of Baseline Respiratory Variables}

Detailed results of analyses are reported in tables 2 and 3. Forest plots are provided as supplementary data. None of the variables meta-analyzed were available in at least 10 studies. Therefore, only fixed-effects models were performed for all the variables.

Comparisons between PD and Social Phobia. All the details are reported in table 2 . Baseline mean RR was significantly higher in subjects with PD than in subjects with social phobia (SP), both when including and excluding nulleffect sizes, respectively $\left(h_{i}=0.333 ; h_{e}=0.473\right)$. Instead, the summary effect sizes of mean TV and MV indicated no significant differences between PD and SP. For the summary effect sizes of the mean et- $\mathrm{pCO}_{2}$, the comparisons were significant when both including and excluding null effect sizes, indicating lower baseline et- $\mathrm{pCO}_{2}$ in subjects with PD than with SP $\left(h_{i}=-0.283 ; h_{e}=-0.51\right)$. Summary effect sizes of venous $\mathrm{pCO}_{2}$ and $\mathrm{HCO}_{3}{ }^{-}$were significant and indicate lower venous $\mathrm{pCO}_{2}(\mathrm{~h}=-0.562)$ and lower venous concentrations of $\mathrm{HCO}_{3}{ }^{-}(\mathrm{h}=-0.785)$ in subjects with PD than in subjects with SP. Instead, the summary effect size estimates for venous $\mathrm{pH}$ were not significant.

Evidence of heterogeneity was found for mean TV (excluding null-effect sizes) and venous $\mathrm{pH}$, as indicated by the significant Q statistics, and for mean MV (excluding null-effect sizes) as suggested by $\mathrm{I}^{2}$. Since only two independent studies were available, the one-by-one exclusion procedure was not performable.

Comparisons between PD and Generalized Anxiety Disorder. All details are reported in table 3. The summary effect size of mean RR comparisons indicates a signifi-

Panic-Specific Respiratory Abnormalities cantly higher mean RR in subjects with $\mathrm{PD}$ than in subjects with GAD $\left(h_{i}=0.259 ; h_{e}=0.297\right)$, both when including and excluding null-effect sizes, whereas the summary effect sizes was not significant for mean MV. Summary effect sizes of mean et- $\mathrm{pCO}_{2}$ were significant, both when including and excluding null-effect sizes, indicating lower et-pCO ${ }_{2}$ in subjects with $\mathrm{PD}$ than in subjects with generalized anxiety disorder $\left(G A D ; h_{i}=-0.420 ; h_{e}=-0.505\right)$.

The significance of $\mathrm{Q}$ statistics demonstrated betweenstudy heterogeneity for mean RR and mean et- $\mathrm{PCO}_{2}$. Analyses identified the mean RR effect size of Munjack et al. [7] as the primary source of heterogeneity in the summary effect size. The exclusion of this study drastically reduced such heterogeneity whereas, by applying the oneby-one exclusion procedure for all the other single-study effect sizes, the Q statistic remained significant. Indeed, the mean RR effect size of Munjack et al. [7] was the lone indication of a significantly higher mean RR in the PD group than in the GAD group, with an effect size extremely large in magnitude $(\mathrm{h}=1.276)$. Meta-analysis of the mean RR performed with the exclusion of Munjack et al. [7] did not indicate a significant difference between $\mathrm{PD}$ and GAD (table 3). Instead, analyses for mean et- $\mathrm{pCO}_{2}$ could not identify any particular effect size as the primary source of heterogeneity (detailed results available upon request).

Moderator Analyses. Moderator analyses (i.e. psychotropic medication washout, medical screening, type of study, catheter, position of the subjects during assessment, or structured or semi-structured diagnostic interview) were performed for all variables that showed relevant heterogeneity, except for mean RR comparisons between PD and GAD groups since the one-by-one study 
Table 1. Baseline respiratory parameters and coded characteristics and of included studies

\begin{tabular}{|c|c|c|c|c|c|c|c|c|c|}
\hline Study & Respiratory parameter & $\begin{array}{l}\text { Statistic of } \\
\text { respiratory } \\
\text { parameter }\end{array}$ & $\begin{array}{l}\text { PD } \\
\text { compared } \\
\text { to }\end{array}$ & Study type & $\begin{array}{l}\text { Subjects' } \\
\text { position }\end{array}$ & $\begin{array}{l}\text { Cath- } \\
\text { eter }\end{array}$ & $\begin{array}{l}\text { Psychotropic } \\
\text { drug } \\
\text { wash-out } \\
\text { criteria }\end{array}$ & $\begin{array}{l}\text { Diagnostic } \\
\text { interview }\end{array}$ & $\begin{array}{l}\text { Medical screening } \\
\text { and no subjects } \\
\text { affected by } \\
\text { respiratory } \\
\text { diseases (PD } \\
\text { subjects + controls) }\end{array}$ \\
\hline $\begin{array}{l}\text { Asmundson } \\
\text { and Stein, } 1994 \text { [42] }\end{array}$ & Respiration rate, et-pCO $2(\mathrm{~mm} \mathrm{Hg})$ & mean & SP & stimulation & seated & no & yes & yes & yes \\
\hline $\begin{array}{l}\text { Asmundson } \\
\text { and Stein, } 1994 \text { [43] }\end{array}$ & Et-pCO $2(\mathrm{~mm} \mathrm{Hg})$ & mean & SP & stimulation & seated & no & no & yes & yes \\
\hline $\begin{array}{l}\text { Blechert } \\
\text { et al., } 2007 \text { [20] }\end{array}$ & $\begin{array}{l}\text { Et-pCO }{ }_{2}(\mathrm{~mm} \mathrm{Hg}) ; \text { Ribcage contribution to } \\
\text { Tidal Volume; rate of sighs ( }>200 \% \text { tidal } \\
\text { volume) }\end{array}$ & mean & PTSD & stimulation & seated & no & no & yes & yes \\
\hline \multirow[t]{2}{*}{$\begin{array}{l}\text { Burkhardt } \\
\text { et al., } 2010 \text { [34] }\end{array}$} & $\begin{array}{l}\text { Respiration rate, tidal volume, minute } \\
\text { ventilation, et- } \mathrm{pCO}_{2}(\mathrm{~mm} \mathrm{Hg}) \text {, duty cycle, } \\
\text { inspiration flow }\end{array}$ & mean & \multirow[t]{2}{*}{ SP } & \multirow[t]{2}{*}{ rest } & \multirow[t]{2}{*}{ seated } & \multirow[t]{2}{*}{ no } & \multirow[t]{2}{*}{ no } & \multirow[t]{2}{*}{ yes } & \multirow[t]{2}{*}{ yes } \\
\hline & $\begin{array}{l}\text { Respiration rate, tidal volume, minute } \\
\text { ventilation, et-p } \mathrm{CO}_{2}(\mathrm{~mm} \mathrm{Hg}) \text {, duty cycle, } \\
\text { inspiration flow }\end{array}$ & rMSSD & & & & & & & \\
\hline \multirow[t]{2}{*}{$\begin{array}{l}\text { Gorman } \\
\text { et al., } 1990[38]\end{array}$} & $\begin{array}{l}\text { Respiration rate, tidal volume, minute } \\
\text { ventilation }\end{array}$ & mean & \multirow[t]{2}{*}{ SP } & \multirow[t]{2}{*}{ stimulation } & \multirow[t]{2}{*}{ seated } & \multirow[t]{2}{*}{ yes } & \multirow[t]{2}{*}{ yes } & \multirow[t]{2}{*}{ no } & \multirow[t]{2}{*}{ no } \\
\hline & $\begin{array}{l}\text { Venous } \mathrm{pCO}_{2} \text {, venous } \mathrm{HCO}_{3}^{-} \text {, venous } \mathrm{pH} \text {, } \\
\text { venous } \mathrm{PO}_{4}^{-}\end{array}$ & - & & & & & & & \\
\hline $\begin{array}{l}\text { Hegel and } \\
\text { Ferguson, } 1997[44]\end{array}$ & Respiration rate, et-pCO $2(\mathrm{~mm} \mathrm{Hg})$ & mean & GAD & stimulation & seated & no & no & yes & yes \\
\hline $\begin{array}{l}\text { Munjack } \\
\text { et al., } 1993[7]\end{array}$ & Respiration rate, et- $\mathrm{pCO}_{2}(\mathrm{~mm} \mathrm{Hg})$ & mean & GAD & rest & seated & no & no & no & no \\
\hline \multirow[t]{2}{*}{$\begin{array}{l}\text { Papp } \\
\text { et al., } 1993[45]\end{array}$} & $\begin{array}{l}\text { Respiration rate, tidal volume, minute } \\
\text { ventilation }\end{array}$ & mean & \multirow[t]{2}{*}{ SP } & \multirow[t]{2}{*}{ stimulation } & \multirow[t]{2}{*}{ supine } & \multirow[t]{2}{*}{ yes } & \multirow[t]{2}{*}{ yes } & \multirow[t]{2}{*}{ no } & \multirow[t]{2}{*}{ yes } \\
\hline & Venous $\mathrm{pCO}_{2}$, venous $\mathrm{HCO}_{3}{ }^{-}$, venous $\mathrm{pH}$ & - & & & & & & & \\
\hline $\begin{array}{l}\text { Rapee, } \\
1986[35]\end{array}$ & Minute ventilation, et- $\mathrm{pCO}_{2}(\mathrm{~mm} \mathrm{Hg})$ & mean & GAD & stimulation & seated & no & no & no & yes \\
\hline $\begin{array}{l}\text { Rapee } \\
\text { et al., } 1992[46]\end{array}$ & Respiration rate, et-pCO $2(\mathrm{~mm} \mathrm{Hg})$ & mean & $\begin{array}{l}\text { GAD, SP, } \\
\text { OCD, } \\
\text { SimpP }\end{array}$ & stimulation & seated & no & no & yes & yes \\
\hline $\begin{array}{l}\text { Roth } \\
\text { et al., } 1998 \text { [37] }\end{array}$ & $\begin{array}{l}\text { Respiration rate, tidal volume, minute } \\
\text { ventilation, et-p } \mathrm{CO}_{2}(\mathrm{~mm} \mathrm{Hg}) \text {, duty cycle, } \\
\text { inspiration flow, length of inspiration, pause } \\
\text { after inspiration, length of expiration, pause } \\
\text { after expiration }\end{array}$ & mean & GAD & stimulation & seated & no & yes & yes & yes \\
\hline \multirow[t]{2}{*}{$\begin{array}{l}\text { Wilhelm } \\
\text { et al., } 2001 \text { [9] }\end{array}$} & $\begin{array}{l}\text { Respiration rate, tidal volume, minute } \\
\text { ventilation, et- } \mathrm{pCO}_{2}(\mathrm{~mm} \mathrm{Hg}) \text {, duty cycle, } \\
\text { inspiration flow }\end{array}$ & mean & \multirow[t]{2}{*}{ SP } & \multirow[t]{2}{*}{ stimulation } & \multirow[t]{2}{*}{ seated } & \multirow[t]{2}{*}{ no } & \multirow[t]{2}{*}{ yes } & \multirow[t]{2}{*}{ yes } & \multirow[t]{2}{*}{ no } \\
\hline & Respiration rate, tidal volume & $\begin{array}{l}\text { complex } \\
\text { demodulation }\end{array}$ & & & & & & & \\
\hline \multirow[t]{5}{*}{$\begin{array}{l}\text { Wilhelm } \\
\text { et al., } 2001 \\
{[8,47]}\end{array}$} & $\begin{array}{l}\text { Respiration rate, tidal volume, tidal volume - } \\
\text { sighs removed, minute ventilation, et-pCO } \mathrm{CO}_{2} \\
(\mathrm{~mm} \mathrm{Hg}) \text {, rate of apneas }(>5 \mathrm{~s}) \text {, duty cycle, in- } \\
\text { spiratory drive, length of sighs ( }>200 \% \text { tidal } \\
\left.\text { volume; } \mathrm{n}^{\circ} / \mathrm{min}\right)\end{array}$ & mean & GAD & rest & seated & no & yes & yes & yes \\
\hline & Respiratory rate, tidal volume & SD & & & & & & & \\
\hline & Tidal volume & rMSSD & & & & & & & \\
\hline & $\begin{array}{l}\text { Respiration rate, tidal volume, tidal volume - } \\
\text { sighs removed, minute ventilation, et- } \mathrm{pCO}_{2} \\
(\mathrm{~mm} \mathrm{Hg}) \text {, duty cycle, inspiratory drive }\end{array}$ & $\begin{array}{l}\text { complex } \\
\text { demodulation }\end{array}$ & & & & & & & \\
\hline & Rate of sighs (>200\% tidal volume) & - & & & & & & & \\
\hline
\end{tabular}

The value indicated in the colunms 'Psychotropic drug wash-out (weeks)' and 'Occasional use of benzodiazepine suspension (days)' refer to the subjects with minimum period of suspension; n.a. = information not available; n.t. = not under treatment; PTSD = post-traumatic stress disorder; OCD = Obsessive Compulsive Disorder; SimpP = Simple Phobia; rMSSD $=$ root mean square of the successive differences. 
Table 2. Meta-analysis comparisons between PD and SP groups

\begin{tabular}{|c|c|c|c|c|c|c|c|c|c|c|}
\hline $\begin{array}{l}\text { Baseline respiratory } \\
\text { parameters }\end{array}$ & $\begin{array}{l}\text { Studies, } \\
\mathrm{n}\end{array}$ & $\mathrm{PD}, \mathrm{n}$ & $\mathrm{SP}, \mathrm{n}$ & g & $95 \% \mathrm{CI}$ & $\mathrm{Z}$ & $\mathrm{p}$ & Q & $\mathrm{p}$ & $\mathrm{I}^{2}$ \\
\hline \multicolumn{11}{|l|}{ Mean } \\
\hline \multicolumn{11}{|l|}{ RR (breath/min) } \\
\hline Including null e-s & 6 & 148 & 128 & 0.333 & 0.092 to 0.575 & 2.704 & $0.007^{*}$ & 5.157 & 0.397 & 3.038 \\
\hline Excluding null e-s & 4 & 114 & 85 & 0.473 & 0.185 to 0.761 & 3.220 & $0.001^{*}$ & 2.100 & 0.552 & 0.000 \\
\hline Excluding null e-s & 2 & 20 & 27 & 0.092 & -0.480 to 0.664 & 0.317 & 0.752 & 4.174 & $0.041^{*}$ & 76.041 \\
\hline \multicolumn{11}{|l|}{$\mathrm{MV}(\mathrm{l} / \mathrm{min})$} \\
\hline Including null e-s & 4 & 64 & 70 & 0.182 & -0.159 to 0.522 & 1.045 & 0.296 & 3.918 & 0.270 & 23.432 \\
\hline Excluding null e-s & 2 & 30 & 27 & 0.439 & -0.091 to 0.968 & 1.623 & 0.105 & 2.374 & 0.123 & 57.872 \\
\hline \multicolumn{11}{|l|}{ et- $\mathrm{PCO}_{2}(\mathrm{~mm} \mathrm{Hg})$} \\
\hline $\begin{array}{l}\text { Including null e-s } \\
\text { Excluding null e-s }\end{array}$ & 2 & 32 & 37 & -0.562 & -1.039 to -0.085 & -2.309 & $0.021^{*}$ & 0.156 & 0.693 & 0.000 \\
\hline \multicolumn{11}{|c|}{ Venous $\mathrm{HCO}_{3}(\mathrm{mmol} / \mathrm{l})$} \\
\hline $\begin{array}{l}\text { Including null e-s } \\
\text { Excluding null e-s }\end{array}$ & 2 & 32 & 37 & -0.785 & -1.270 to -0.299 & -3.167 & $0.002^{*}$ & 0.061 & 0.805 & 0.000 \\
\hline \multicolumn{11}{|l|}{ Venous $\mathrm{pH}$} \\
\hline $\begin{array}{l}\text { Including null e-s } \\
\text { Excluding null e-s }\end{array}$ & 2 & 32 & 37 & -0.037 & -0.512 to 0.438 & -0.153 & 0.879 & 4.175 & $0.041^{*}$ & 76.051 \\
\hline
\end{tabular}

Table 3. Meta-analysis of comparisons between PD and GAD groups

\begin{tabular}{|c|c|c|c|c|c|c|c|c|c|c|}
\hline $\begin{array}{l}\text { Baseline respiratory } \\
\text { parameters }\end{array}$ & $\begin{array}{l}\text { Studies, } \\
\mathrm{n}\end{array}$ & $\begin{array}{l}\mathrm{PD} \\
\mathrm{n}\end{array}$ & $\begin{array}{l}\text { GAD, } \\
\mathrm{n}\end{array}$ & $\mathrm{g}$ & $95 \% \mathrm{CI}$ & $\mathrm{Z}$ & $\mathrm{p}$ & Q & $\mathrm{p}$ & $\mathrm{I}^{2}$ \\
\hline \multicolumn{11}{|l|}{ Mean } \\
\hline Including null e-s & 5 & 191 & 131 & 0.259 & 0.029 to 0.489 & 2.203 & $0.028^{*}$ & 37.092 & $0.000^{*}$ & 89.216 \\
\hline Excluding null e-s & 4 & 172 & 114 & 0.297 & 0.050 to .544 & 2.361 & $0.018^{*}$ & 36.371 & $0.000^{*}$ & 91.752 \\
\hline \multicolumn{11}{|l|}{$\mathrm{RR}^{\mathrm{a}}$ (breath/min) } \\
\hline Excluding null e-s & 3 & 108 & 66 & -0.269 & -0.578 to 0.041 & -1.700 & 0.089 & 1.385 & 0.500 & 0.000 \\
\hline \multicolumn{11}{|l|}{$\operatorname{MV}(1 / \min )$} \\
\hline Including null e-s & 3 & 55 & 45 & 0.250 & -0.140 to 0.639 & 1.258 & 0.209 & 2.354 & 0.308 & 15.050 \\
\hline Excluding null e-s & 2 & 36 & 28 & 0.397 & -0.094 to 0.888 & 1.585 & 0.113 & 1.419 & 0.234 & 29.509 \\
\hline \multicolumn{11}{|l|}{ et- $\mathrm{PCO}_{2}(\mathrm{~mm} \mathrm{Hg})$} \\
\hline
\end{tabular}

* Fixed-effects models: $\mathrm{p}<$ 0.05; for Q statistics: $\mathrm{p}<0.1 . \mathrm{h}=$ Hedges' g. e-s = Effect sizes. ${ }^{\text {a }}$ Excluding Munjack et al. [7]. 
exclusion procedure had already identified the outlying effect size of Munjack et al. [7] as the source of heterogeneity for this variable. No moderator analyses were significant (detailed results available upon request).

\section{Publication Bias}

Detailed results of Egger's regression tests are provided as supplementary data. Egger's regression tests were significant only for mean et- $\mathrm{pCO}_{2}(\mathrm{PD}$ vs. GAD) when the null-effect sizes were excluded from the analysis $(\mathrm{p}=$ 0.016). Instead, Egger's regression tests were not significant when effect sizes coded as null were inserted. As in [6], the strategy to include null-effect sizes to overcome the bias of unreported nonsignificant results was efficacious.

\section{Discussion}

Our meta-analytic results showed significant differences on baseline respiratory variables between subjects with PD and those with SP or GAD, supporting the idea of specific respiratory abnormalities in PD. Our findings should be considered preliminary because included studies allowed the meta-analysis of only a few respiratory variables and only fixed-effects meta-analytic models could be performed. Further independent studies are needed before more definitive conclusions. No evidence of publication bias was found, suggesting no concerns about possible unpublished data that we did not insert in our meta-analysis.

\section{Comparisons between PD and SP}

Subjects with PD showed significantly lower baseline mean et- $\mathrm{pCO}_{2}$, indicating a condition of hyperventilation, and higher mean RR than subjects with SP, with small-to-moderate differences for both variables [22]. Although the point-estimate of the mean MV summary effect size was positive, suggesting higher global MV in PD, this result did not reach statistical significance, possibly because of the weak statistical power of the analyses. No significant differences were found for mean TV between groups. Higher mean RR in subjects with PD than in those with SP suggests that faster breathing might be a source of hyperventilation in PD. Unfortunately, no data were available to meta-analyze possible differences between PD and SP on indices of respiratory variability/irregularity or rate of sighs/apneas. In fact, these may be a source of hyperventilation in PD [6]. Thus, the available data do not allow fully disentangling the source of the baseline hyperventilation of subjects with PD compared to those with SP.
We also found lower venous partial pressure of $\mathrm{CO}_{2}$, in line with the findings of lower et- $\mathrm{pCO}_{2}$, and lower venous $\mathrm{HCO}_{3}{ }^{-}$concentrations in subjects with $\mathrm{PD}$, whereas no difference in venous $\mathrm{pH}$ was found. The significantly reduced $\mathrm{HCO}_{3}{ }^{-}$concentration without a significant difference in $\mathrm{pH}$ suggests that the lower et- $\mathrm{pCO}_{2}$ in subjects with $\mathrm{PD}$ might arise from chronic hyperventilation, also a condition existing before the experimental assessment procedures.

These findings are not in line with the few available studies employing ambulatory monitoring devices in real-life settings, which have failed to provide any evidence of hyperventilation in $\mathrm{PD}$ by comparing mean $\mathrm{MV}, \mathrm{RR}$ and TV of subjects with PD and controls [19, 23-25]. The reasons for this discrepancy may arise from the limited statistical power achieved in the ambulatory monitoring studies, probably due to the small sample sizes, and from the lack of measuring key variables related to hyperventilation, such as end-tidal or transcutaneous $\mathrm{pCO}_{2}$.

In summary, we found a condition of chronic hyperventilation in subjects with PD compared to those with SP.

\section{Comparisons between $P D$ and $G A D$}

Subjects with PD showed significantly lower baseline mean et- $\mathrm{pCO}_{2}$ than subjects with $\mathrm{GAD}$, indicating a condition of hyperventilation. This difference was medium in magnitude [22]. Subjects with PD showed significantly higher baseline mean RR than subjects with GAD, but no significant difference was found after excluding the outlying effect size of the study by Munjack et al. [7] from the analysis. This study shows several methodological limitations, such as the lack of a diagnostic structured/semistructured interview and the lack of screening of subjects' medical illnesses or respiratory diseases. Thus, the lack of difference on mean RR between PD and GAD seems to be a more reliable meta-analytic result. No significant differences were found for mean MV. Finally, no sufficient data were available to perform meta-analysis on baseline mean TV and other respiratory variables, such as indices of respiratory variability/irregularity or rate of sighs/apneas. For these reasons, the source of the baseline hyperventilation of subjects with $\mathrm{PD}$ compared to those with GAD cannot be found.

\section{Limitations}

The main shortcoming affecting our meta-analysis is the limited number of independent studies available for each comparison. Thus, there were only a few meta-anal-
Grassi/Caldirola/Di Chiaro/Riva/Daccò/ Pompili/Perna 
yses of respiratory and hematic variables, whereas no analyses were performable for several other relevant variables related to respiratory function, including indices of respiratory variability/irregularity and rate of sighs/apneas. In addition, no data were available regarding other ADs than SP and GAD. Due to the small number of single-study effect sizes, only the fixed-effects model was able to be performed, providing less consistent results than the combination of fixed-and random-effects models. Furthermore, because of the weak statistical power, nonsignificant results may either reflect a real lack of difference among the compared groups or be a consequence of the small statistical power achieved by our analyses. Similar limitations may have affected moderator and publication bias analyses.

Other limitations arise from the general poor methodological quality of the studies performed in this field. Several studies did not apply some relevant exclusion criteria in the selection of their samples. When possible we included these variables as moderators, but, for instance, this strategy could not be used for the psychiatric comorbidity because none of the included studies had fully applied this exclusion criterion, and this constitutes a possible source of bias. Samples of subjects with PD and other ADs were often unbalanced for sociodemographic characteristics, thus introducing other potential sources of biases. For instance, gender has a well-known impact on respiration related to the influence of the menstrual cycle on many respiratory variables [26, 27]. Many studies reported data only regarding the significant effect sizes; in order to avoid possible biases arising from the exclusion of nonsignificant comparisons, we applied, when possible, a null-effect size inclusion - a strategy that had been efficacious in our previous meta-analysis [6].

Since the meta-analytic approach is strictly based on the quality of the included studies, a general methodological weakness of the entire field of research makes it difficult for meta-analyses to be applied and to provide reliable answers. In order to reach complete and reliable results, a greater number of independent studies comparing respiratory function between subjects with PD and subjects with other ADs, a greater completeness of the investigated variables, and better methodological designs are necessary.

\section{Conclusions}

Subjects with PD show a condition of baseline hyperventilation when compared with subjects with SP and GAD. Comparisons of hematic variables between PD and
SP suggest that the hyperventilation may be chronic and thus present also before and beyond the experimental respiratory assessment. Our findings support the idea that the respiratory abnormalities might be specific features of the PD pathophysiology not shared with other ADs. However, the source of these abnormalities remains unclear. They may arise from an intrinsic malfunction of the respiratory system, as proposed by [2-4], or be related to emotional/cognitive/behavioral factors [28, 29].

Studies in healthy subjects have found both a positive association between trait anxiety levels and mean RR during mental stress paradigms $[30,31]$ and increased ventilation with reduced et- $\mathrm{pCO}_{2}$ during anticipatory anxiety when waiting for an electrical stimulation [32]. This suggests that anxiety experienced by subjects may modulate their respiration patterns [33]. Subjects with PD may experience more anxiety than subjects with other ADs during experimental laboratory procedures. This may partly explain the discrepancy in the results between ambulatory monitoring and laboratory studies on respiration. Previous studies have found that subjects with PD and those with GAD or SP exhibit equivalent trait anxiety [34-36], and most studies that have measured state-anxiety before respiratory assessment have found similar levels in subjects with PD and in those with GAD or SP [9, 36-38]. This indication, in association with the finding of chronic hyperventilation in $\mathrm{PD}$, suggests that a general temporary condition of state-anxiety related to the experimental setting might not be able to fully account for the respiratory abnormalities of $\mathrm{PD}$. On the contrary, subjects with $\mathrm{PD}$ exhibit peculiar emotional/cognitive/ behavioral features, such as fear of somatic sensations, panic-specific beliefs and phobic/protective behaviors $[39,40]$ that perhaps are not completely captured by simply measuring general levels of trait/state anxiety [41]. Thus, these factors might influence respiration of subjects with PD in a peculiar way, leading to their specific respiratory abnormalities even when compared to subjects with other ADs and exhibiting similar levels of trait/state anxiety.

Further studies specifically investigating these issues are needed to clarify the source of the PD-specific respiratory abnormalities.

\section{Acknowledgements}

This work was performed as a partial fulfillment towards the International Master in Affective Neuroscience of Maastricht University and the University of Florence. The authors thank Sinem Yeşilyurt and Giuseppe Iannone for revising the manuscript. 


\section{References}

$>1$ Niccolai V, van Duinen MA, Griez EJ: Respi- 18 Peters JL, Sutton AJ, Jones DR, Abrams KR, ratory patterns in panic disorder reviewed: a focus on biological challenge tests. Acta Psychiatr Scand 2009;120:167-177.

$\checkmark 2$ Perna G, Caldirola D, Bellodi L: Panic disorder: from respiration to the homeostatic brain. Acta Neuropsychiatr 2004;16:57-67.

-3 Esquivel G, Schruers K, Maddock R, Colasanti A, Griez E: Acids in the brain: a factor in panic? J Psychopharmacol 2010;24:639-647.

4 Klein DF: False suffocation alarms, spontaneous panics, and related conditions. An integrative hypothesis. Arch Gen Psychiatry 1993;50:306-317.

$>5$ Ley R: Blood, breath, and fears: a hyperventilation theory of panic attacks and agoraphobia. Clin Psychol Rev 1985;5:271-285.

-6 Grassi M, Caldirola D, Vanni G, Guerriero G, Piccinni M, Valchera A, Perna G: Baseline respiratory parameters in panic disorder a meta-analysis. J Affect Disord 2013;146:158173.

7 Munjack DJ, Brown RA, McDowell DE: Existence of hyperventilation in panic disorder with and without agoraphobia, GAD, and normals: implications for the cognitive theory of panic. J Anxiety Disord 1993;7:37-48.

$>8$ Wilhelm F, Gevirtz R, Roth W: Respiratory dysregulation in anxiety, functional cardiac, and pain disorders: assessment, phenomenology, and treatment. Behav Modif 2001;25: 513-545.

>9 Wilhelm F, Gerlach A, Roth W: Slow recovery from voluntary hyperventilation in panic disorder. Psychosom Med 2001;63:638-649.

10 Diagnostic and Statistical Manual of Mental Disorders, ed 3. Washington, American Psychiatric Association, 1980.

11 Diagnostic and Statistical Manual of Mental Disorders, ed 3, rev. Washington, American Psychiatric Association, 1987.

12 Diagnostic and Statistical Manual of Mental Disorders, ed 4. Washington, American Psychiatric Association, 1992.

13 Diagnostic and Statistical Manual of Mental Disorders, ed 4, text rev (DSM-IV TR). Washington, American Psychiatric Association, 2000.

14 Hedges LV, Olkin I: Statistical Methods for Meta-Analysis. Waltham, Academic Press, 1985.

15 Petitti DB: Approaches to heterogeneity in meta-analysis. Stat Med 2001;20:3625-3633.

$>16$ Egger M, Davey Smith G, Schneider M, Minder C: Bias in meta-analysis detected by a simple, graphical test. BMJ 1997;315:629-634.

17 Duval S, Tweedie R: Trim and fill: a simple funnel-plot-based method of testing and adjusting for publication bias in meta-analysis. Biometrics 2000;56:455-463.
Rushton L: Performance of the trim and fill method in the presence of publication bias and between-study heterogeneity. Stat Med 2007;26:4544-4562.

19 Hoehn-Saric R, McLeod DR, Funderburk F, Kowalski P: Somatic symptoms and physiologic responses in generalized anxiety disorder and panic disorder: an ambulatory monitor study. Arch Gen Psychiatry 2004;61:913921.

20 Blechert J, Michael T, Grossman P, Lajtman $\mathrm{M}$, Wilhelm FH: Autonomic and respiratory characteristics of posttraumatic stress disorder and panic disorder. Psychosom Med 2007;69:935-943.

-21 van Den Hout MA, Hoekstra R, Arntz A, Christiaanse M, Ranschaert W, Schouten E: Hyperventilation is not diagnostically specific to panic patients. Psychosom Med 1992;54: 182-191.

22 Cohen J: Statistical Power Analysis for the Behavioral Sciences, ed 2. Hillsdale, Erlbaum Associates, 1988.

23 Martinez JM, Papp LA, Coplan JD, Anderson DE, Mueller CM, Klein DF, Gorman JM: Am bulatory monitoring of respiration in anxiety. Anxiety 1996;2:296-302.

24 Pfaltz MC, Grossman P, Michael T, Margraf J, Wilhelm FH: Physical activity and respiratory behavior in daily life of patients with panic disorder and healthy controls. Int J Psychophysiol 2010;78:42-49.

25 Pfaltz MC, Michael T, Grossman P, Blechert J, Wilhelm FH: Respiratory pathophysiology of panic disorder: an ambulatory monitoring study. Psychosom Med 2009;71:869-876.

26 Behan M, Wenninger JM: Sex steroidal hormones and respiratory control. Respir Physiol Neurobiol 2008;164:213-221.

27 Macnutt MJ, De Souza MJ, Tomczak SE, Homer JL, Sheel AW: Resting and exercise ventilatory chemosensitivity across the menstrual cycle. J Appl Physiol 2012;112:737-747.

28 Gorman JM, Kent JM, Sullivan GM, Coplan JD: Neuroanatomical hypothesis of panic disorder, revised. Am J Psychiatry 2000;157: 493-505.

29 Clark DM: A cognitive approach to panic. Behav Res Ther 1986;24:461-470.

30 Masaoka Y, Homma I: Anxiety and respiratory patterns: their relationship during mental stress and physical load. Int J Psychophysiol 1997;27:153-159.

31 Masaoka Y, Homma I: Expiratory time determined by individual anxiety levels in humans. J Appl Physiol 1999;86:1329-1336.

32 Masaoka Y, Homma I: The effect of anticipatory anxiety on breathing and metabolism in humans. Respir Physiol 2001;128:171-177.
33 Homma I, Masaoka Y: Breathing rhythms and emotions. Exp Physiol 2008;93:10111021.

34 Burkhardt SCA, Wilhelm FH, Meuret AE Blechert J, Roth WT: Temporal stability and coherence of anxiety, dyspnea, and physiological variables in panic disorder. Biol Psychol 2010;85:226-232.

35 Rapee R: Differential response to hyperventilation in panic disorder and generalized anxiety disorder. J Abnorm Psychology 1986;95: 24-28.

36 Wilhelm FH, Trabert W, Roth WT: Physiologic instability in panic disorder and generalized anxiety disorder. Biol Psychiatry 2001; 49:596-605.

37 Roth W, Wilhelm F, Trabert W: Voluntary breath holding in panic and generalized anxiety disorders. Psychosom Med 1998;60:671679.

38 Gorman JM, Papp LA, Martinez J, Goetz RR, Hollander E, Liebowitz MR, Jordan F: Highdose carbon dioxide challenge test in anxiety disorder patients. Biol Psychiatry 1990;28: 743-757.

39 Naragon-Gainey K: Meta-analysis of the relations of anxiety sensitivity to the depressive and anxiety disorders. Psychol Bull 2010;136: 128-150.

40 Perugi G, Frare F, Toni C: Diagnosis and treatment of agoraphobia with panic disorder. CNS Drugs 2007;21:741-764.

41 McNally RJ: Is anxiety sensitivity distinguishable from trait anxiety? Reply to Lilienfeld, Jacob, and Turner (1989). J Abnorm Psychol 1989;98:193-194.

42 Asmundson G, Stein M: Triggering the false suffocation alarm in panic disorder patients by using a voluntary breath-holding procedure. Am J Psychiatry 1994;151:264-266.

43 Asmundson G, Stein M: Vagal attenuation in panic disorder: an assessment of parasympathetic nervous system function and subjective reactivity to respiratory manipulations. Psychosom Med 1994;56:187-193.

44 Hegel MT, Ferguson RJ: Psychophysiological assessment of respiratory function in panic disorder: evidence for a hyperventilation subtype. Psychosom Med 1997;59:224-230.

$\checkmark 4$ Papp L, Klein D, Gorman J: Carbon dioxide hypersensitivity, hyperventilation, and panic disorder. Am J Psychiatry 1993;150:11491157.

46 Rapee RM, Brown TA, Antony MM, Barlow $\mathrm{DH}$ : Response to hyperventilation and inhalation of $5.5 \%$ carbon dioxide-enriched air across the DSM-III-R anxiety disorders. J Abnorm Psychol 1992;101:538-552.

47 Wilhelm F, Trabert W, Roth W: Characteristics of sighing in panic disorder. Biol Psychiatry 2001;49:606-614. 